University of Nebraska - Lincoln

DigitalCommons@University of Nebraska - Lincoln

Publications from USDA-ARS / UNL Faculty

U.S. Department of Agriculture: Agricultural

Research Service, Lincoln, Nebraska

November 1992

\title{
Simulating winter wheat shoot apex phenology
}

G. S. McMaster

USDA-ARS, greg.mcmaster@ars.usda.gov

Wallace Wilhelm

University of Nebraska-Lincoln, wwilhelm1@unl.edu

J. A. Morgan

USDA-ARS

Follow this and additional works at: https://digitalcommons.unl.edu/usdaarsfacpub

Part of the Agricultural Science Commons

McMaster, G. S.; Wilhelm, Wallace; and Morgan, J. A., "Simulating winter wheat shoot apex phenology " (1992). Publications from USDA-ARS / UNL Faculty. 104.

https://digitalcommons.unl.edu/usdaarsfacpub/104

This Article is brought to you for free and open access by the U.S. Department of Agriculture: Agricultural Research Service, Lincoln, Nebraska at DigitalCommons@University of Nebraska - Lincoln. It has been accepted for inclusion in Publications from USDA-ARS / UNL Faculty by an authorized administrator of DigitalCommons@University of Nebraska - Lincoln. 


\title{
Simulating winter wheat shoot apex phenology
}

\author{
G. S. MCMASTER ${ }^{1 *}$, W. W. WILHELM ${ }^{2}$ AND J. A. MORGAN ${ }^{1}$ \\ ${ }^{\prime}$ USDA-ARS, Crops Research Laboratory, 1701 Centre Avenue, Fort Collins, CO 80526, USA \\ ${ }^{2}$ USDA-ARS, Agronomy Department, University of Nebraska, Lincoln, NE 68583, USA
}

(Revised MS received 13 November 1991)

\begin{abstract}
SUMMARY
Simulation models are heuristic tools for integrating diverse processes and help to increase our understanding of complex processes and systems. Models that predict crop development can serve as decision-support tools in crop management. This paper describes a phenology simulation model for the winter wheat shoot apex and reports validation and sensitivity analysis results.

The complete developmental sequence of the winter wheat shoot apex is quantitatively outlined and correlated with commonly recognised phenological growth stages. The phyllochron is used to measure the thermal time between most phenological growth stages, thereby increasing the flexibility over the growing degree-day (GDD) and photothermal approaches. Nineteen site-years covering a range of climatic conditions, cultural practices and cultivars across the Central Great Plains, USA, are used to validate the model.

Validation results show that the predicted phyllochron (108 GDD) agrees well with the observed phyllochron (107 GDD) for ten cultivars. Mean seedling emergence is predicted to within 2 days in almost all of the 19 site-years. The ability of the model to predict growth stages accurately increased successively from jointing to heading to maturity. Maturity is generally predicted to within 5 days of the observed day.

After validation, recalibration of the phyllochron estimates between growth stages are provided, and corrections for mesic and xeric conditions are suggested. Further validation of the entire developmental sequence of the shoot apex is recommended.
\end{abstract}

\section{INTRODUCTION}

Much research has been directed in the last decade towards understanding the development and growth of the winter wheat (Triticum aestivum $\mathrm{L}$. em Thell) shoot apex (Masle-Meynard \& Sebillotte 1981; Klepper et al. 1982, 1984; Kirby 1985; Delecolle et al. 1989; Kirby et al. 1989). Little of this research has been consolidated into mechanistic models. With few exceptions (Weir et al. 1984; Ritchie \& Otter 1985; McMaster et al. 1991), most of the 76 wheat yieldpredicting models known to us do not simulate near the level of shoot apex function, and developmental processes are not emphasised.

Predicting crop development is important both for crop growth and development models and also as an aid in scheduling cultural practices. Traditionally some variation of the number of days, growing degree-days, or photothermal units approach has often been used to estimate the interval between growth stages (French \& Hodges 1985; McMaster \&

\footnotetext{
* Present address: USDA-ARS, Great Plains Systems Research, PO Box E, Fort Collins, CO 80522, USA.
}

Smika 1988). This empirically-based approach works well with many crops. An alternative approach using the phyllochron as a measure of the thermal interval between growth stages shows promise, both because it is more flexible than the other approaches and because it integrates developmental processes within the plant.

This paper discusses the determination of the thermal interval between winter wheat growth stages using the phyllochron approach for most intervals, the incorporation of the phyllochron thermal estimates into a simulation model for predicting winter wheat shoot apex phenology and the evaluation of the approach by validation and sensitivity analysis.

\section{MATERIALS AND METHODS}

Model conceptualization

This model simulates the phenology of the shoot apex daily from planting to maturity. Computer code is standard FORTRAN 77 and the model runs on machines with the UNIX, VMS, and MS-DOS operating systems.

Some distinguishing features of this model are (i) the entire developmental sequence of the shoot apex is 
quantitatively outlined and correlated with easily identified growth stages, (ii) an alternative approach based on the number of phyllochrons, rather than growing degree-days (GDD) or photothermal units, is used to estimate the interval between most growth stages, (iii) the growth stages are predicted for different age classes, or cohorts, of plants determined by the time of emergence, thus introducing a population element into the model and (iv) within an age class, the growth stage is calculated for morphologically identified culms, thus incorporating the variability observed within a plant.

The sequence of developmental events along a growth stage time line was derived from the literature and personal observation. In Fig. 1, the developmental sequence of the shoot apex is correlated with commonly recognised phenological growth stages (as defined in Bauer et al. 1983) from germination (G) to physiological maturity (M). Areas of uncertainty are indicated by question marks. Uncertainty may result either from (i) conflicting or variable reports found in the literature, (ii) cultivar variation or (iii) lack of available data.

The developmental sequence applies to all plants within a stand, but clearly not all plants within a stand are at the same phenological growth stage. A population element has been incorporated into the model to address the variation among plants observed by having different age classes, or cohorts, of plants (Wilhelm et al. 1990; McMaster et al. 1991). Based on time of emergence, according to a normal curve that is influenced by the percentage water-filled pore space, plants are grouped into an age class. The growth stage of the median plant of the cohort is then simulated.

Just as there is variability in growth stage among plants within a stand, there is also variability among culms within a plant. The growth stage of each culm within a plant of a specific age class is simulated in this model. The morphological nomenclature used in this model (Klepper et al. 1983) allows each culm to be identified. Culms are either the main stem (MS) or tillers. Tillers are designated as primary tillers (e.g. $\mathrm{T} 0, \mathrm{~T} 1, \mathrm{~T} 2)$, secondary tillers (e.g. T10, T11), tertiary tillers (e.g. T110, T111) and so forth.

The fundamental concept involved in predicting development and the thermal interval between many growth stages is the phyllochron. The phyllochron is defined as the mean time, in accumulated growing degree-days (GDD), for successive leaf blades to appear. In calculating GDD, a base temperature of $0^{\circ} \mathrm{C}$ is used in this model (Gallagher 1979; Gallagher et al. 1979). The observed tendency for a constant phyllochron throughout the life of a plant is simulated (Friend 1965; Baker et al. 1980; Masle-Meynard \& Sebillotte 1981; Kirby et al. 1982, 1989 for wheat and barley; Klepper et al. 1982; Rawson et al. 1983; Malvoisin 1984; Belford et al. 1987; Kirby \& Perry
1987; Delecolle et al. 1989), although occasional unpredictable shifts in the phyllochron during the growing season have been observed (e.g. Hay \& Delecolle 1989; Boone et al. 1990). The length of the phyllochron has been related to change in day length at emergence (Baker et al. 1980; Kirby et al. 1982, $1985 a$ for wheat and barley; Delecolle et al. 1985; Kirby \& Perry 1987; Wright \& Hughes 1987 for spring barley). The corrected algorithm from Baker et al. (1980) used to calculate the length of the phyllochron in units of GDD is:

$$
\text { phyllochron }=\frac{1}{(0 \cdot 026 \times \Delta d)+0 \cdot 0104}
$$

where $\Delta d=$ change in day length $(\mathrm{h})$ of successive days at the time of emergence. Because cohorts emerge on different days, the change in day length will vary, causing the calculated phyllochron to vary, and thus developmental rates will differ slightly among plants in different cohorts.

The phyllochron concept provides a useful technique for estimating leaf, tiller and root appearance based on main stem Haun growth stage (Klepper et al. 1984) and internode elongation. Other developmental rates, such as spikelet primordium initiation rates, are often related to leaf appearance rates by some constant multiplier of the phyllochron.

If time is measured in accumulated growing degreedays, then the phyllochron is the same as the GDD model, but more flexible as shown below. Varying rates of plant development are observed in the field due to different planting dates or latitude (Baker et al. 1990; Hay \& Wilson 1982; Kirby et al. 1982, 1985a, b, for wheat and barley; Crofts et al. 1984; Klepper et al. 1985; Saini et al. 1986; Thomson 1986; Batten \& Khan 1987; Kirby \& Perry 1987). For example, Nuttonson (1948) reported that the GDD from seedling emergence to heading for Marquis wheat generally decreased as emergence was delayed. Masoni et al. (1990) showed a decrease in GDD required to reach all phenological growth stages for spring sowings as opposed to autumn sowings. Given that the phyllochron predicted by Baker et al. (1980) decreases with later planting dates, then using the dynamic phyllochron approach, rather than the static GDD approach, should reflect this trend more accurately.

Despite the apparent advantages of the phyllochron concept to measure time between phenological growth stages, use of the technique has not been reported, although Rickman \& Klepper (1991) give some estimates of the number of phyllochrons between several growth stages. Fully vernalized cultivars with moderate photoperiod sensitivity reach single ridge (SR) 1-2 phyllochrons after the photoperiod begins to increase in late winter. Commonly in models, 1 January is chosen as the beginning of increasing 


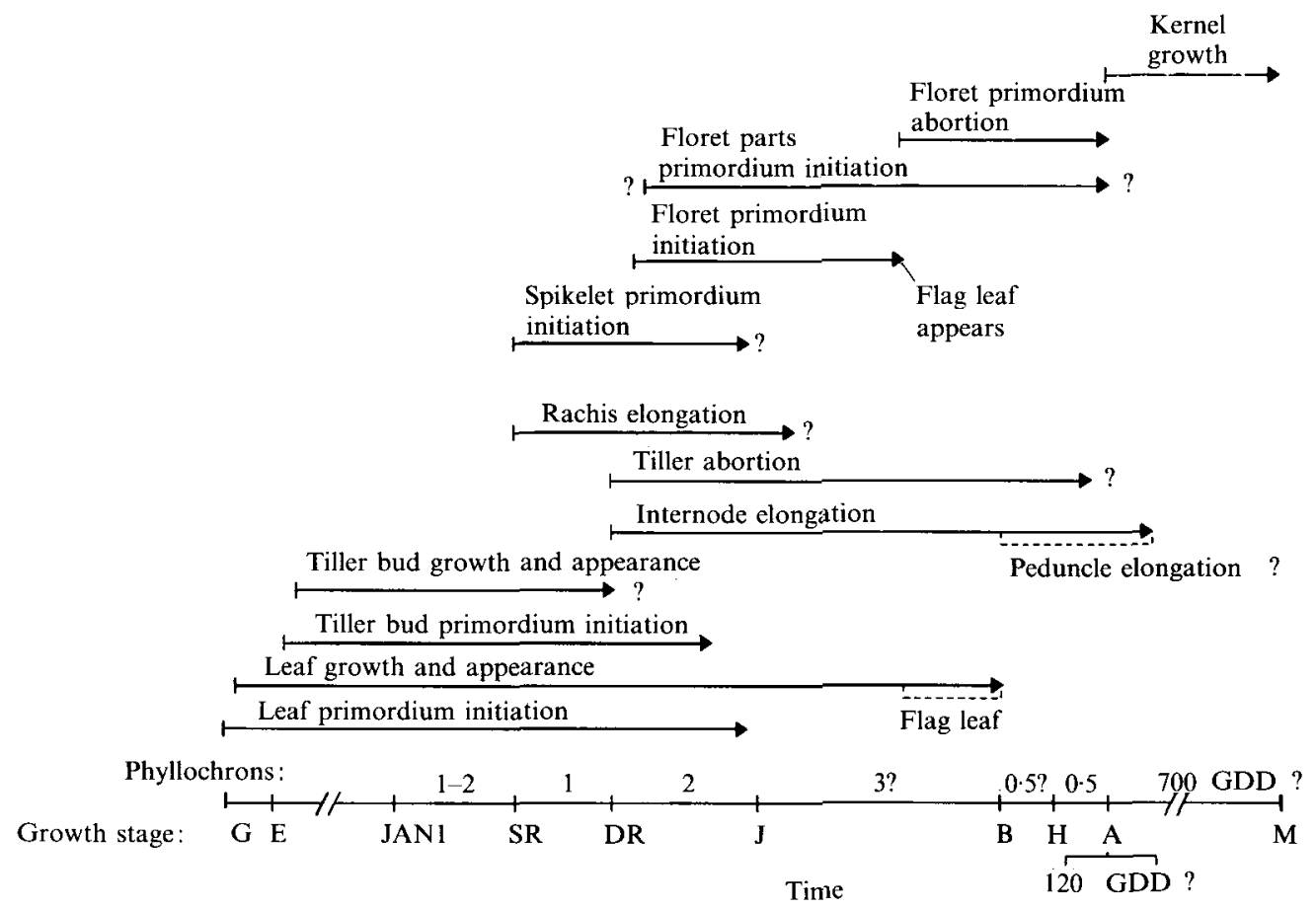

Fig. 1. Developmental sequence of the shoot apex correlated with the phenological growth stages of germination (G), seedling emergence (E), single ridge (SR), double ridge (DR), jointing (J), booting (B), heading (H), anthesis (A) and physiological maturity (M). Leaf appearance is the time when the youngest expanding lamina can be seen emerging from the enclosing penultimate leaf. Question marks indicate areas of uncertainty or variability due to cultivars, environment, conflicting reports in the literature or lack of available data.
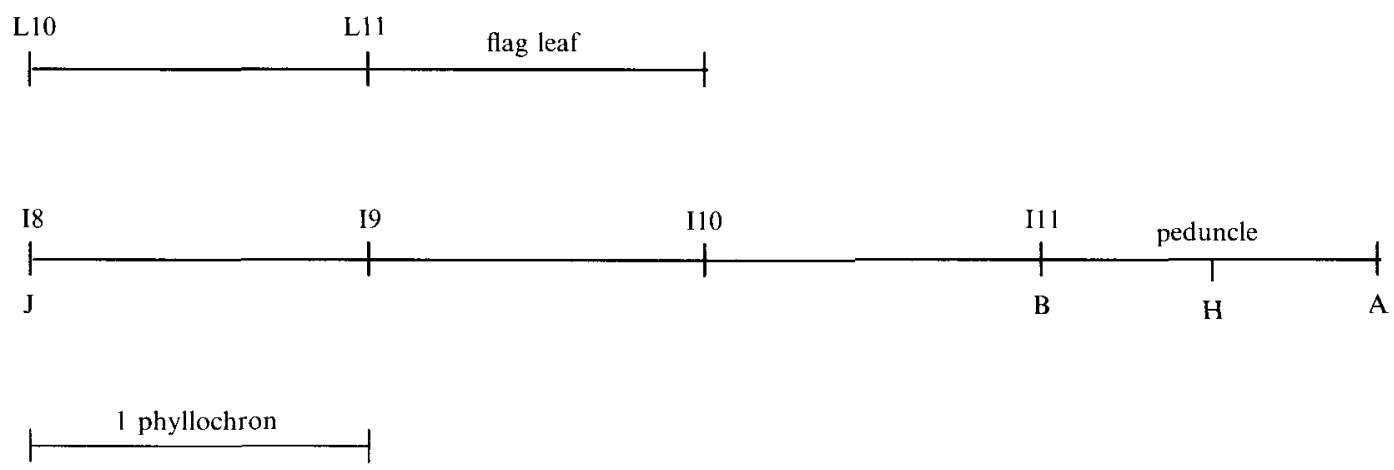

Fig. 2. Assumptions for estimating the number of phyllochrons from jointing ( $\mathrm{J}$ ) to anthesis (A). B = booting, $\mathrm{H}=\mathrm{heading}$, L10 and L11 = leaf 10 and 11 (L11 = flag leaf in this example, although the flag leaf number can be any positive integer number $<21$ ), I8, I9, I10 and I11 = nodes plus associated internodes (I11 = peduncle in this example). See text for a full explanation.

photoperiod for the Northern Hemisphere. Double ridge (DR) follows about 1 phyllochron after single ridge, and jointing $(\mathrm{J})$, beginning when the first node is visible $25 \mathrm{~mm}$ above the soil surface, 2 phyllochrons after double ridge. Anthesis (A) is about 0.5 phyllochrons after heading $(\mathrm{H})$. We have adopted these estimates in the model, with single ridge being estimated as being 1.5 phyllochrons after 1 January.

Because estimates for the number of phyllochrons between the intervals from jointing to booting (B) could not be found in the literature, the estimate was determined as follows. If two leaves are allowed to 
Table 1. Comparison of observed to predicted phyllochron in growing degree-days $(G D D)$ above a $0^{\circ} \mathrm{C}$ base temperature

\begin{tabular}{|c|c|c|c|}
\hline Cultivar & $\begin{array}{l}\text { Observed } \\
\text { phyllochron } \\
\text { (GDD) }\end{array}$ & $\begin{array}{l}\text { Standard } \\
\text { error }\end{array}$ & $\begin{array}{c}\text { Maturity } \\
\text { class }\end{array}$ \\
\hline Agate & 107 & $5 \cdot 4$ & 5 \\
\hline Baca & 104 & $2 \cdot 5$ & 3 \\
\hline Bezostaya & 98 & $2 \cdot 3$ & 5 \\
\hline Centurk 78 & 111 & $5 \cdot 4$ & 5 \\
\hline Century & 107 & $3 \cdot 4$ & 4 \\
\hline Chisholm & 108 & 1.4 & 1 \\
\hline Stephens & 108 & $8 \cdot 7$ & 6 \\
\hline Sturdy & 105 & $5 \cdot 1$ & 3 \\
\hline TAM 101 & 109 & $2 \cdot 3$ & 1 \\
\hline Vona & 110 & $1 \cdot 7$ & 2 \\
\hline Mean & $106 \cdot 9$ & $1 \cdot 3$ & - \\
\hline $\begin{array}{c}\text { Emergence } \\
\text { date }\end{array}$ & $\begin{array}{l}\text { Predicted } \\
\text { phyllochron } \\
\text { (GDD) }\end{array}$ & & \\
\hline September 25 & $108 \cdot 6$ & & \\
\hline September 27 & 108.6 & & \\
\hline September 30 & 108.5 & & \\
\hline October 2 & $108 \cdot 5$ & & \\
\hline October 5 & $108 \cdot 4$ & & \\
\hline October 10 & $108 \cdot 2$ & & \\
\hline October 15 & 107.9 & & \\
\hline
\end{tabular}

Observed results are from the 1986 field experiment; predicted phyllochron is from Baker et al. (1980). Latitude was $40^{\circ} 30^{\prime}$. Various emergence dates are shown, with the best estimate of $50 \%$ emergence being 2 October. Maturity class is from Haley (1989), with larger numbers representing later maturity dates. A Kruskal-Wallis nonparametric test showed no significant difference between cultivars in the phyllochron $(P>0.42)$. No significant correlation was found between the phyllochron and maturity class.

appear after jointing and internode elongation is set to lag 2 phyllochrons after the associated leaf appears, as simulated in the model, then the peduncle will begin elongation when booting is first reached (Fig. 2). This means that booting will begin 2 phyllochrons after the flag leaf appears and 3 phyllochrons after jointing. Some flexibility is incorporated into the model by allowing the flag leaf to appear at variable times. At jointing, the current leaf on each culm completes its growth, and then two more leaves (penultimate and flag) are allowed to appear. This allows a variance of slightly less than \pm 0.5 phyllochrons in the time from jointing to growth stages from booting to maturity.

Heading and anthesis growth stages typically follow closely after booting, even though booting is often variably defined. Nuttonson (1955) reported an average of 9-10 days from booting to heading and 5-6 days from heading to anthesis for a spring wheat. Masoni et al. (1990) showed 15 and 8 days (138 and 146 GDD) between $B$ and $H$, and $H$ and $A$, respectively for an autumn sowing, and 7 days for both intervals for a spring sowing (128 and 132 GDD, respectively). Given that temperature increases slightly from booting to anthesis, the GDD for the intervals of $B$ to $H$ and $H$ to $A$ are slightly closer despite the difference of $c .4$ days duration of the two intervals. Unfortunately, the number of phyllochrons from booting to heading has not been reported in the literature, but Rickman \& Klepper (1991) estimate c. 0.5 phyllochrons between heading and anthesis. Rawson \& Evans (1970) suggest c. 4 days (66 GDD) between ear emergence and anthesis for the wheat variety Triple Dirk. If average daily air temperature is $20{ }^{\circ} \mathrm{C}$ (typical for Fort Collins, at the time of heading), and the phyllochron is 109 GDD (Table 1), then half a phyllochron equates to $c .55$ GDD or 3 days. The same number of phyllochrons (0.5) was assumed between both intervals ( $B$ to $H$ and $H$ to $A$ ). By making this assumption of 1 phyllochron between $B$ and $\mathrm{A}$, consistency in the model is maintained by allowing each internode to elongate over a period of 1 phyllochron. This means that the peduncle begins elongating at booting and ends at anthesis.

Using the number of phyllochrons does not seem to offer any advantages over the number of GDD for estimating the duration of anthesis and grain filling, in part because of the nonlinear response of the duration of these processes to temperature (Spiertz \& Vos 1985; Vos 1985; Herzog 1986). Therefore, the GDD approach with $0{ }^{\circ} \mathrm{C}$ base temperature is used in this model for these two intervals. The default value for the duration of anthesis is 120 GDD (6 days at an average daily temperature of $20^{\circ} \mathrm{C}$, based on unpublished glasshouse data). To predict grain filling duration for all kernels within a spike, it was assumed that at an average daily temperature of $20^{\circ} \mathrm{C}$ it would take 35 days, or 700 GDD (based on a general survey of literature and unpublished data).

Since all kernels within a spike do not commence grain filling simultaneously (Bonnett 1966; Rawson \& Evans 1970; Oosterhuis 1977), a separate estimate of the duration of grain filling for each kernel is necessary, since the growth of each kernel is simulated daily in this model. Most studies show that as temperature increases, the duration of individual grain filling decreases, although the relationship with GDD is not linear and there are large differences among cultivars (Wiegand \& Cuellar 1981; Bhullar \& Jenner 1983; Sayed \& Ghandorah 1984; Herzog 1986). As a result, the user inputs at least two data points for the duration of grain filling for a kernel and the mean temperature during this period. Then a linear or log-linear relationshp is used (selected by the user) to calculate a regression equation of mean 


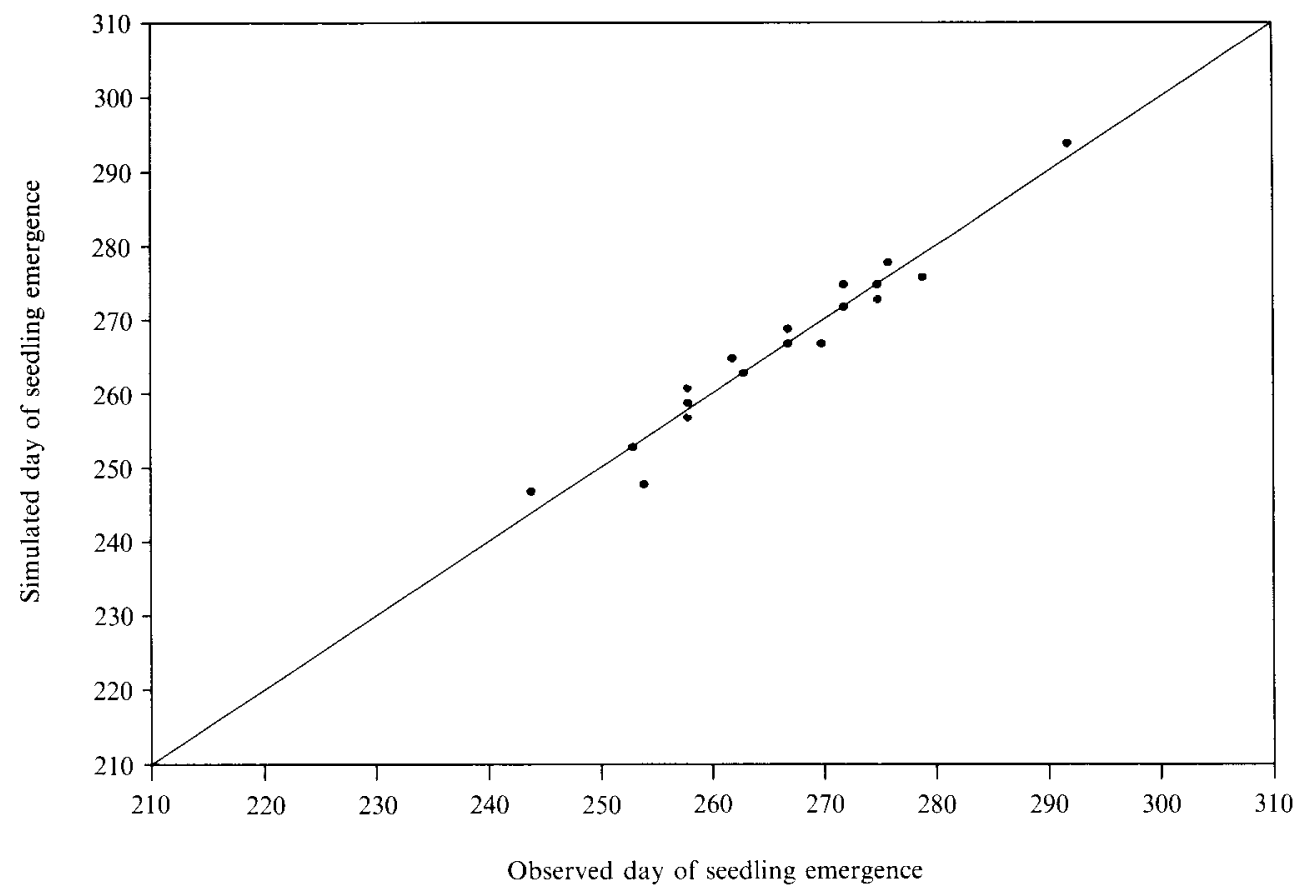

Fig. 3. Comparison of simulated with observed calendar day number of seedling emergence. The original estimates from the time line in Fig. 1 are used for the simulation predictions. The observed data are from McMaster \& Smika (1988). Planting depth was to a layer with adequate soil water for germination, but a planting depth of $30 \mathrm{~mm}$ was assumed for all site-years. RMSE (root mean square error) $=2 \cdot 4$.

temperature during grain filling on duration of grain filling. The model accumulates GDD, beginning with the first day of anthesis and tallies a cumulative mean temperature for each kernel to calculate when an individual kernel reaches maturity, based on the regression equation input by the user.

Because effects of nutrients, water and photoperiod are secondary to temperature in altering phenology (McMaster \& Smika 1988) and qualitative relationships are so unclear that quantification is difficult, the model assumes that temperature alone controls phenological development rates. Since the model calculates the $\mathrm{N}$ and water availability and photoperiod daily, an algorithm could be developed by the user to change the number of phyllochrons and GDD between various growth stages according to different $\mathrm{N}$ and water levels and photoperiod.

Through jointing, the main stems of all cohorts normally reach the same phenological growth stage simultaneously in the model, because most cohorts normally emerge over a period of 1-2 days and the phyllochron does not change greatly for small differences in emergence dates. For growth stages after jointing, the main stem of successively younger age classes reaches a specific growth stage successively later. All culms within a cohort reach the same phenological growth stage simultaneously, except that culms within a cohort are staggered for the appearance of flag leaves, end of floret primordium initiation and beginning of floret primordium abortion. The code is constructed to allow the user to incorporate an algorithm for stagger for other growth stages among the culms on a plant if so desired.

\section{Validation data sets}

Data sets for 19 site-years as described by McMaster \& Smika (1988) were used to test the model. The 19 site-years were for seven dryland sites across the Central Great Plains, USA (Medford, OK; Garden City, Mankato and Tribune, KS; Akron, CO; Paxton, $\mathrm{NE}$; and Albin, WY), using four different winter wheat cultivars (Centurk, Larned, Scout 66 and TAM 101) and a variety of soil types and cultural practices (e.g. rotations, row spacing, fertilizer). Data were collected from 1977 to 1980 (planting dates). The growth stages of seedling emergence, jointing, heading and physiological maturity were observed for main stems. Several inputs affecting the model, such as planting density, planting depth and stand density, had to be approximated when using these data sets to validate the model.

The root mean square error (RMSE), sum of the residuals (SRES), and sum of the absolute residuals 
(SARES) are useful measures for estimating variation and bias in a model. These measures are defined in the following equations;

$$
\begin{aligned}
\text { RMSE } & =\left[\frac{\sum_{i=1}^{n}\left(\mathrm{OBS}_{i}-\mathrm{SIM}_{i}\right)^{2}}{n}\right]^{\frac{1}{2}} \\
\text { SRES } & =\sum_{i=1}^{n}\left(\mathrm{OBS}_{i}-\mathrm{SIM}_{i}\right) \\
\text { SARES } & =\sum_{i=1}^{n}\left|\mathrm{OBS}_{i}-\mathrm{SIM}_{i}\right|
\end{aligned}
$$

where $\mathrm{OBS}_{i}$ is the observed calendar day of the event in question, $\operatorname{SIM}_{i}$ is the simulated calendar day of occurrence and $n$ is the number of $\mathrm{OBS}_{i}-$ SIM $_{i}$ pairs. A small RMSE suggests close agreement between simulated and observed values. The SRES and SARES are useful in determining how errors in the model cancel. If SRES is small compared to SARES, errors in the model will tend to cancel. If SRES and SARES are large and SRES is positive, the model tends to underestimate the observed value (i.e. the simulated day of the growth stage is earlier than the observed day). However, if SRES is negative and large in comparison to SARES, then the model will tend to overestimate the observed value (i.e. the simulated day is later than the observed day).

A field experiment was conducted to test the predicted phyllochron for ten cultivars of winter wheat grown on a Nunn clay loam (Aridic Arguistoll) at the Colorado State University Horticulture Farm at Fort Collins, CO, USA. Daily maximum and minimum air temperature, precipitation and incident PAR radiation data were collected at the site.

Ten winter wheat cultivars were planted in late September 1986: Agate, Baca, Bezostaya, Centurk 78, Century, Chisholm, Stephens, Sturdy, TAM 101 and Vona. These cultivars were chosen to provide a range of drought-tolerance and height classes at maturity. The Haun growth stage (Haun 1973) for each culm on ten to fifteen plants/plot was randomly sampled on 31 December 1986, with four replicate plots/cultivar. The phyllochron for each cultivar was determined by dividing the number of growing degree-days from seedling emergence by the Haun growth stage.

\section{RESULTS}

The algorithm of Baker et al. (1980) does not incorporate cultivar or stress variations into predicting the phyllochron and was developed for an English cultivar (Maris Huntsman) at one site in England. To determine how well the algorithm predicted the phyllochron for some commonly used cultivars in the Central Great Plains, results from the field experiment were used (Table 1). A KruskalWallis test showed no significant difference $(P>0.42)$ in the phyllochron between cultivars, although Bezostaya (a tall cultivar bred in the Soviet Union) had the lowest mean observed phyllochron. Data from glasshouse experiments (not shown) and personal observation also suggested that Bezostaya had a lower phyllochron than some of the semi-dwarfs such as Vona. Pooling the ten cultivars gave a mean phyllochron of $107 \mathrm{GDD}\left(0^{\circ} \mathrm{C}\right.$ base temperature $)$, which compared very well with the value of 108 GDD predicted by Baker et al. (1980). Caution is needed in extrapolating these results to other planting dates, as other planting dates have not been validated for Great Plains conditions and cultivars. No significant correlation was found between the maturity class and phyllochron.

The seedling emergence model is important in part because this submodel defines the day of emergence of the three seedling cohorts and, as a result, their phyllochrons. If we assume that the Baker et al. (1980) algorithm reasonably predicts the phyllochron for an emergence date, and if the seedling emergence submodel can predict the time of emergence to within a few days, then the phyllochron should be reasonably correct for use in the phenology submodel. When the simulated date of $50 \%$ seedling emergence was compared with the observed date for 19 site-years (Fig. 3), most predictions were within 2 days of the observed date. The RMSE was quite low $(2.4$; Table 2$)$ for predicting seedling emergence, and sRES was small $(-4 \cdot 0)$ compared to SARES (34.0), suggesting there was no bias in the submodel.

The RMSE error decreased successively for jointing, heading and maturity growth stages (RMSE $=13 \cdot 5,9 \cdot 4$ and 8.2, respectively; Table 2, Figs 4, 5 and 6). McMaster \& Smika (1988) discussed some of the problems in predicting jointing, particularly the varying vernalization requirements of winter wheat cultivars and the influence of photoperiod, which this model does not incorporate. Much of the variability in predicting jointing was probably due to yearly variations in vernalization conditions, resulting in vernalization (full or partial) occurring at different photoperiods. In examining the SRES and SARES for J, $\mathrm{H}$ and $\mathrm{M}$ (Table 2), jointing tends to be predicted late, no model bias is exhibited for heading and maturity is slightly late. McMaster \& Smika (1988) and others have shown that mild water stress tends to hasten phenological development. If so, the model should be biased towards predicting late for the dryland conditions of the validation data sets. Therefore, many of the time line estimates from $J$ to $M$ in Fig. 1 need to be increased for conditions of optimal water availability.

The interval from $\mathbf{J}$ to $\mathbf{H}$ was evaluated by setting the model to the observed day of $J$ and then comparing simulated day to the observed day of $\mathrm{H}$ (Fig. 5; 
Table 2. Phenology submodel validation using line estimates from Fig. 1

\begin{tabular}{|c|c|c|c|c|c|c|c|c|}
\hline & \multicolumn{2}{|c|}{ Seedling emergence } & \multicolumn{2}{|c|}{ Jointing } & \multicolumn{2}{|c|}{ Heading } & \multicolumn{2}{|c|}{ Maturity } \\
\hline & OBS & SIM & OBS & SIM & OBS & SIM & OBS & SIM \\
\hline $\begin{array}{l}\text { Mean day number } \\
\text { date (day/month) }\end{array}$ & $\begin{array}{c}266 \cdot 4 \\
(23 / 9)\end{array}$ & $\begin{array}{c}266 \cdot 6 \\
(24 / 9)\end{array}$ & $\begin{array}{l}120 \cdot 7 \\
(1 / 5)\end{array}$ & $\begin{array}{l}123 \cdot 7 \\
(4 / 5)\end{array}$ & $\begin{array}{l}152 \cdot 2 \\
(1 / 6)\end{array}$ & $\begin{array}{l}152 \cdot 1 \\
(1 / 6)\end{array}$ & $\begin{array}{l}186 \cdot 9 \\
(6 / 7)\end{array}$ & $\begin{array}{l}187 \cdot 5 \\
(6 / 7)\end{array}$ \\
\hline Range & $244-292$ & $247-294$ & $109-138$ & $104-143$ & $136-177$ & $130-172$ & $165-206$ & $167-211$ \\
\hline Range of differences & \multicolumn{2}{|c|}{-3 to 6} & \multicolumn{2}{|c|}{-24 to 19} & \multicolumn{2}{|c|}{-15 to 23} & \multicolumn{2}{|c|}{-10 to 20} \\
\hline RMSE & \multicolumn{2}{|c|}{$2 \cdot 4$} & \multicolumn{2}{|c|}{13.5} & \multicolumn{2}{|c|}{$9 \cdot 4$} & \multicolumn{2}{|c|}{$8 \cdot 2$} \\
\hline SRES & \multicolumn{2}{|l|}{-4} & \multicolumn{2}{|c|}{-56} & \multicolumn{2}{|c|}{2} & \multicolumn{2}{|c|}{-11} \\
\hline SARES & \multicolumn{2}{|l|}{34} & \multicolumn{2}{|c|}{222} & \multicolumn{2}{|c|}{146} & \multicolumn{2}{|c|}{121} \\
\hline
\end{tabular}

The estimates used were 1.5 phyllochrons from 1 January to single ridge, $1 \cdot 0$ phyllochrons from single ridge to double ridge, 2.0 phyllochrons from double ridge to jointing, 3.0 phyllochrons from jointing to booting, 0.5 phyllochrons from booting to heading and heading to anthesis, and 700 growing degree-days from anthesis to maturity. The observed numbers (OBS) are from McMaster \& Smika (1988) and include 19 site-years. RMSE = root mean square error, sRES = sum of the residuals, SARES $=$ sum of the absolute residuals.

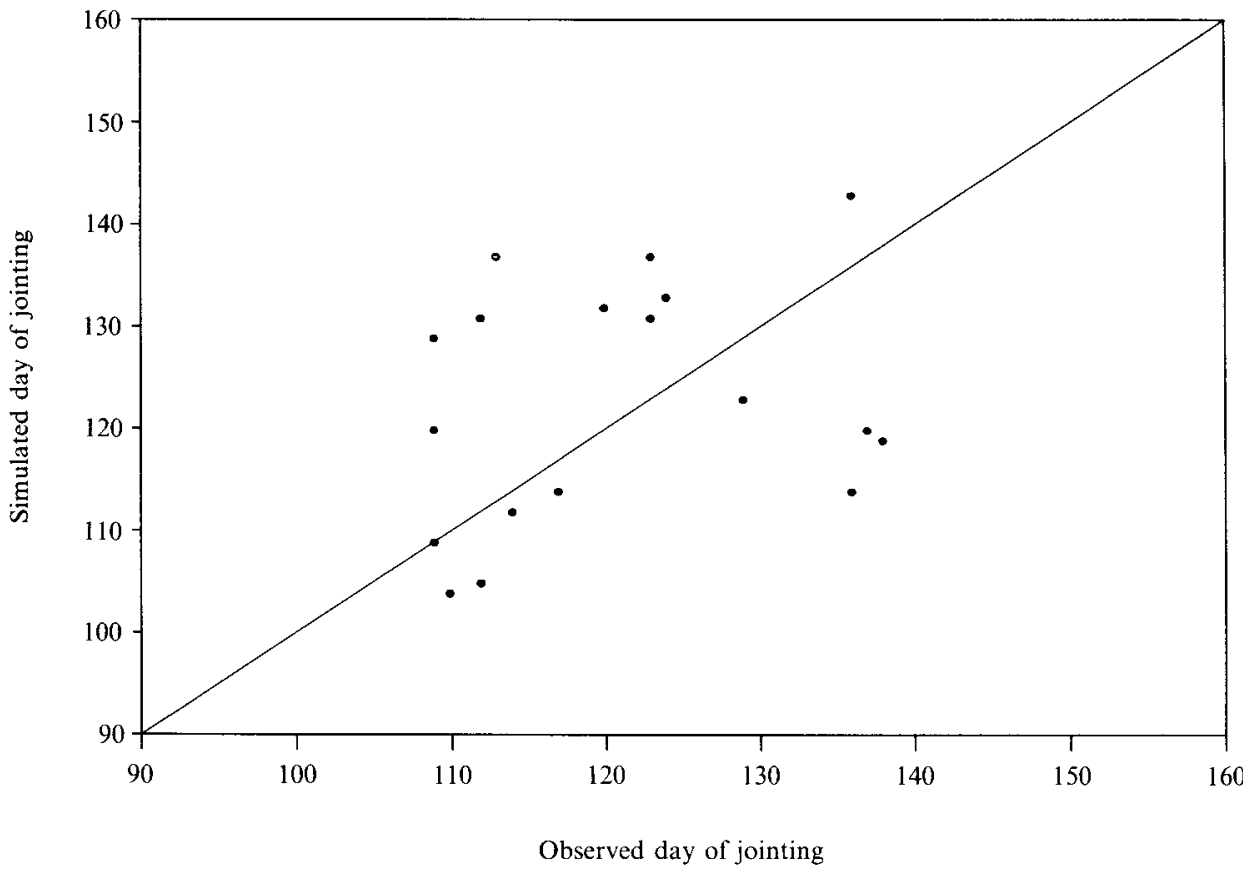

Fig. 4. Comparison of simulated with observed calendar day number of jointing. The original estimates from the time line in Fig. 1 are used for the simulation predictions. The observed data are from McMaster \& Smika (1988). RMSE (root mean square error) $=13 \cdot 5$.

Table 3). When setting the simulated day of jointing equal to the observed, the mean day of heading differed more between the simulated and observed (150.5 and 152.2, respectively) than when using the original estimates and not setting the simulated day of jointing equal to the observed (152.1 and 152.2, respectively). This was the case for maturity as well. The RMSE did decrease when predicting heading with the day of jointing set to the observed. Comparing
SRES to SARES confirmed the results using only the original estimates, that the interval from jointing to heading should be longer than 3.5 phyllochrons.

To validate the interval from $H$ to $M$, the simulated dates of jointing and heading were set equal to the observed (Fig. 6; Table 4). The agreement between the simulated (187.9) and observed (186.9) mean maturity date was better than when only the simulated date of jointing was set equal to the observed 


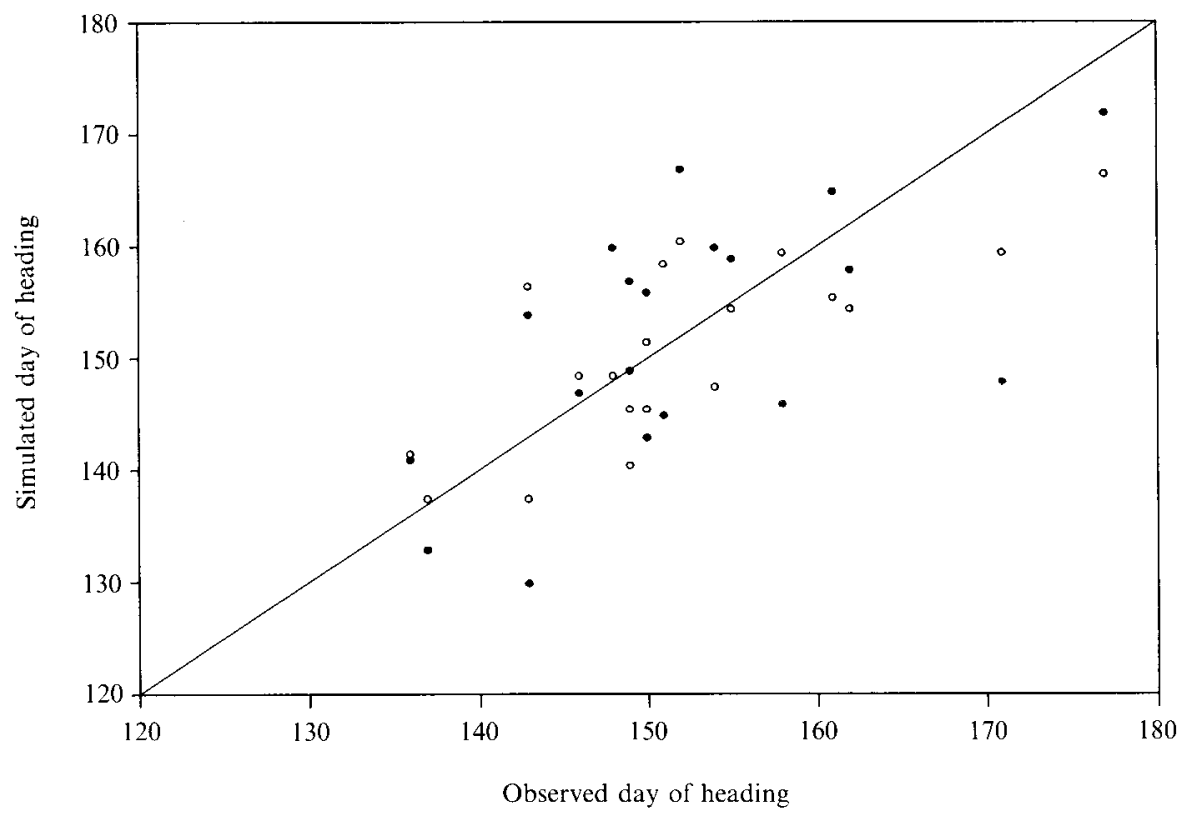

Fig. 5. Comparison of simulated with observed calendar day number of heading. The observed data are from McMaster \& Smika (1988). Two techniques were used to predict heading; using the estimates from the time line in Fig. 1 (O), RMSE (root mean square error $)=9 \cdot 4$; or setting the simulated day of jointing to the observed day $(O)$, RMSE $=6 \cdot 8$. Open circles are a test of the estimated interval from jointing to heading.

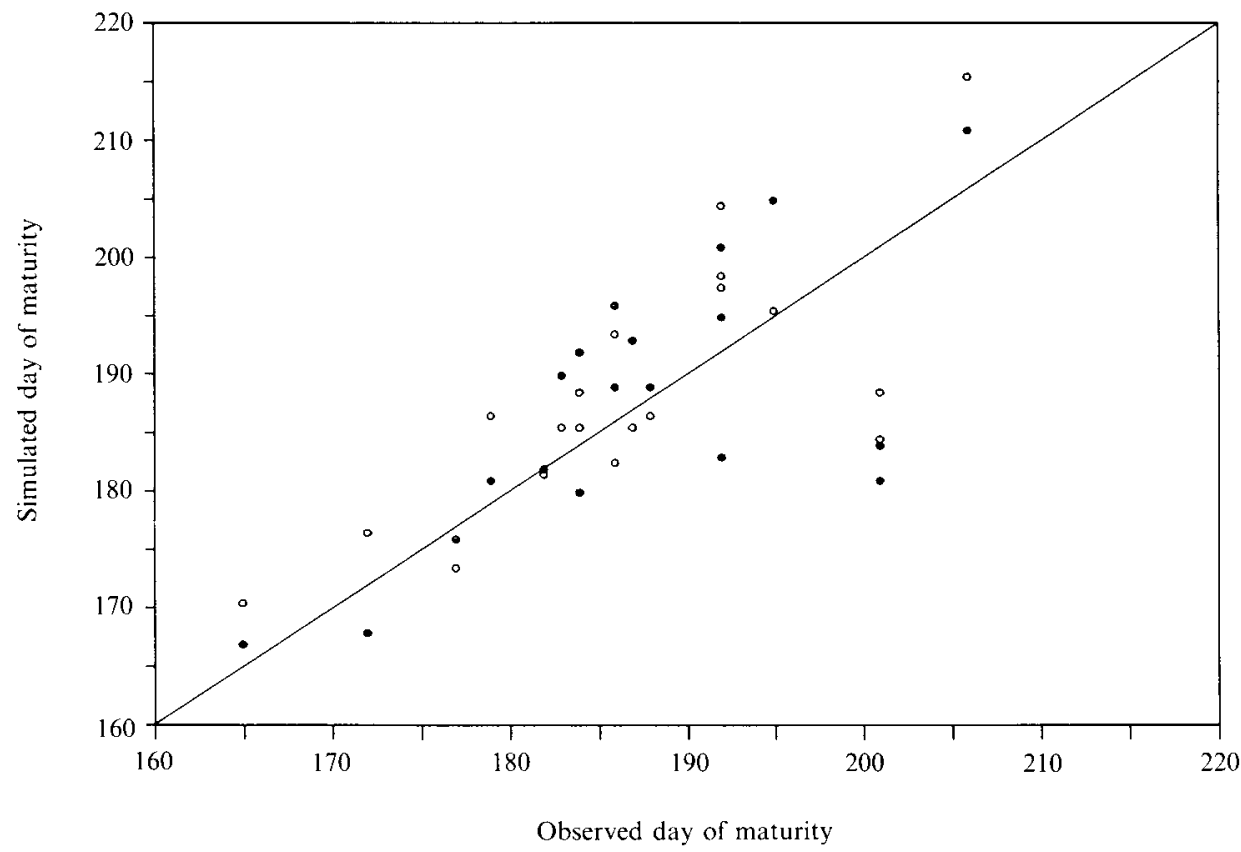

Fig. 6. Comparison of simulated with observed calendar day number of maturity. The observed data are from McMaster \& Smika (1988). Two techniques were used to predict maturity; using the estimates from the time line in Fig. 1 (O), RMSE (root mean square error) $=8 \cdot 2$; or setting the simulated days of jointing and heading to the observed days $(O)$, $\mathrm{RMSE}=7 \cdot 1$. Open circles are a test of the estimated interval from heading to maturity. 
Table 3. Phenology submodel validation for the interval from jointing to heading

\begin{tabular}{|c|c|c|c|c|}
\hline & \multicolumn{2}{|c|}{ Heading } & \multicolumn{2}{|c|}{ Maturity } \\
\hline & OBS & SIM & OBS & SIM \\
\hline $\begin{array}{l}\text { Mean day number } \\
\text { date (day/month) }\end{array}$ & $\begin{array}{l}152 \cdot 2 \\
(1 / 6)\end{array}$ & $\begin{array}{c}150 \cdot 5 \\
(30 / 5)\end{array}$ & $\begin{array}{l}186 \cdot 9 \\
(6 / 7)\end{array}$ & $\begin{array}{l}185 \cdot 6 \\
(5 / 7)\end{array}$ \\
\hline Range & $136-177$ & $137-166$ & $165-206$ & $170-207$ \\
\hline Range of differences & \multirow{2}{*}{\multicolumn{2}{|c|}{$\begin{array}{c}-8 \text { to } 12 \\
6.8\end{array}$}} & \multicolumn{2}{|c|}{-6 to 14} \\
\hline RMSE & & & \multicolumn{2}{|c|}{$5 \cdot 2$} \\
\hline SRES & \multicolumn{2}{|c|}{32} & \multirow{2}{*}{\multicolumn{2}{|c|}{$\begin{array}{r}7 \\
69\end{array}$}} \\
\hline SARES & \multicolumn{2}{|c|}{106} & & \\
\hline
\end{tabular}

The estimates used are given in Table 2, except that the interval from 1 January to jointing was changed so that the simulated date (SIM) of jointing would coincide with the observed date (OBS, from McMaster \& Smika 1988). RMSA, SRES and SARES are as defined in Eqns 2, 3, and 4. $n=19$.

Table 4. Phenology submodel validation for the interval from heading to maturity

\begin{tabular}{lcc}
\hline & \multicolumn{2}{c}{ Maturity } \\
\cline { 2 - 3 } & OBS & SIM \\
\cline { 2 - 3 } & 186.9 & 187.9 \\
Mean day number & $(6 / 7)$ & $(7 / 7)$ \\
date (day/month) & $165-206$ & $170-215$ \\
Range & -12 to 17 \\
Range of differences & $7 \cdot 1$ \\
RMSE & -19 \\
SRES & 105 \\
SARES & - \\
\hline
\end{tabular}

The estimates used are given in Table 2, except that the intervals from 1 January to jointing and jointing to booting were changed so that the simulated days (SIM) of jointing and heading would coincide with the observed days (OBS, from McMaster \& Smika 1988). RMSE, SRES and SARES are as defined in Eqns 2, 3, and 4. $n=19$.
Table 6. Sensitivity analysis for changing the thermal estimates for various growth stage intervals

\begin{tabular}{llll}
\hline \hline Interval changed & $-10 \%$ & Zero & $+10 \%$ \\
\hline 1 January to single ridge & $188 \cdot 0$ & $188 \cdot 8$ & $189 \cdot 5$ \\
Single ridge to double ridge & $188 \cdot 4$ & $188 \cdot 8$ & $189 \cdot 2$ \\
Double ridge to jointing & $188 \cdot 0$ & $188 \cdot 8$ & $189 \cdot 6$ \\
Jointing to booting & $187 \cdot 4$ & $188 \cdot 8$ & $190 \cdot 2$ \\
Booting to heading & $188 \cdot 7$ & $188 \cdot 8$ & $189 \cdot 2$ \\
Heading to anthesis & 188.7 & $188 \cdot 8$ & $189 \cdot 2$ \\
Anthesis to maturity & $185 \cdot 8$ & $188 \cdot 8$ & 191.7 \\
\hline
\end{tabular}

Thermal estimates were changed by $\pm 10 \%$ of the original estimates given in the time line of Fig. 1 . The effect on the date of maturity is given.

$(\mathrm{SIM}=185 \cdot 6, \mathrm{OBS}=186 \cdot 9)$. Neither of these adjustments resulted in as accurate a prediction as when using the original estimates for all growth stages $(\mathrm{SIM}=187 \cdot 5, \quad$ OBS $=186 \cdot 9)$. The RMSE for the

Table 5. Observed (OBS) and estimated (EST) thermal time in growing degree-days (GDD) above a base temperature of $0^{\circ} \mathrm{C}$ between various growth stages

\begin{tabular}{|c|c|c|c|c|c|c|c|c|}
\hline \multirow[b]{2}{*}{ Cultivar } & \multicolumn{2}{|c|}{1 January-Jointing } & \multicolumn{2}{|c|}{ Jointing-Heading } & \multicolumn{2}{|c|}{ Heading-Maturity } & \multicolumn{2}{|c|}{1 January-Maturity } \\
\hline & $\begin{array}{c}\text { OBS } \\
\text { (GDD) }\end{array}$ & $\begin{array}{c}\text { EST } \\
\text { (GDD) }\end{array}$ & $\begin{array}{l}\text { OBS } \\
\text { (GDD) }\end{array}$ & $\begin{array}{c}\text { EST } \\
\text { (GDD) }\end{array}$ & $\begin{array}{c}\text { OBS } \\
\text { (GDD) }\end{array}$ & $\begin{array}{c}\text { EST } \\
\text { (GDD) }\end{array}$ & $\begin{array}{l}\text { OBS } \\
\text { (GDD) }\end{array}$ & $\begin{array}{c}\text { EST } \\
\text { (GDD) }\end{array}$ \\
\hline Centurk 78 & 410 & - & 415 & - & 821 & - & 1646 & - \\
\hline Scott 66 & 512 & - & 489 & - & 715 & - & 1716 & - \\
\hline Larned & 508 & - & 420 & - & 704 & - & 1632 & - \\
\hline TAM 101 & 584 & - & 462 & - & 659 & - & 1705 & 一 \\
\hline Mean & 471 & 487 & 440 & 379 & 758 & 754 & 1668 & 1620 \\
\hline
\end{tabular}

Observed values are from McMaster \& Smika (1988) and are for all cultivars combined and by cultivar. A phyllochron of 108.2 was used in converting from the number of phyllochrons in the interval to GDD. The algorithm for predicting the phyllochron does not distinguish between cultivars, so the estimated thermal time for each cultivar is the same as the mean. 
maturity growth stage was lowest when only the simulated date of jointing was set to the observed (5.2), intermediate when the simulated dates of jointing and heading were set to the observed (7.1) and highest when using the original estimates for all growth stages $(8 \cdot 2)$. The SRES and SARES for setting the simulated dates of jointing and heading, suggest that 0.5 phyllochrons plus 700 GDD is about correct for predicting the interval from $\mathbf{H}$ to $\mathbf{M}$ under Central Great Plains dryland conditions.

Another way to evaluate the phenology model is to compare the observed thermal time between growth stages with the estimated thermal time. To convert the number of phyllochrons in an interval to GDD in the interval, the estimated GDD/phyllochron is multiplied by the number of phyllochrons. The mean estimated phyllochron for the 19 site-year simulations equalled 108.2 GDD, with a range from 106.7109.1 GDD. In Table 5, the observed and estimated GDDs are shown. When comparing the observed to estimated thermal time, it is clear that 3.5 phyllochrons from jointing to heading is too low by at least 0.6 phyllochrons ( 60 GDD). The estimated thermal time for the intervals from 1 January to jointing, heading to maturity and 1 January to maturity are close to the observed thermal time. If the phenology submodel is to be run on a wide range of dryland conditions throughout the Central Great Plains (i.e. not optimal water conditions), then the time line estimates in Fig. 1 should be changed to 1.4 phyllochrons from 1 January to single ridge, $1 \cdot 1$ phyllochrons from booting to heading and 680 GDD from anthesis to maturity.

Sensitivity analysis was conducted by changing the thermal estimates, one at a time, between most of the growth stages by $\pm 10 \%$ of the original thermal estimates. If the thermal estimates were in number of phyllochrons, then the number of phyllochrons was changed; if the estimate was in GDD, then the number of GDD was changed. Only the effects on the date of maturity will be discussed here. Changing thermal time by $10 \%$ for any of the intervals other than from anthesis to maturity had little significant impact on predicting the day of maturity; changing the interval from anthesis to maturity by $10 \%$ altered the predicted day of maturity by 3 days (Table 6). This suggests that it is not necessary that each thermal estimate be more accurate than $\pm 10 \%$ for predicting maturity adequately (to within 5 days).

\section{DISCUSSION}

The developmental sequence of the shoot apex and phenology model contains the framework necessary to predict the sequence and timing of shoot apex developmental events. Some uncertainty and unexplained variability exists in the complete quantification of the developmental sequence and phenology of the shoot apex, and further research on the timing of and interrelationships between some of the developmental events is needed. Yet to our knowledge, this is the first time that the complete developmental sequence of the shoot apex has been quantitatively integrated with easily identified phenological growth stages. The structure of the model is such that new research can be easily incorporated into the model.

Both the phyllochron and the seedling emergence submodels are critical in influencing the phenology model. The algorithm for predicting the phyllochron performed very well in our validation. This, combined with a close agreement between the predicted and estimated day of $50 \%$ seedling emergence, indicates that the phyllochron predicted for the median cohort, or mean plant in the field, is quite accurate.

In general, the phenology model did well in predicting jointing, heading and maturity growth stages, with successively later growth stages being predicted with greater accuracy. After validating the original thermal estimates between several of the growth stages, the suggested thermal estimates are presented in Table 7 both for dryland and well watered conditions. The dryland estimates were derived from the validation results presented earlier. The estimates for well watered soils were primarily determined by comparing GDD between intervals from high rainfall years to low rainfall years in the 19 site-years validation data set. The values for duration of anthesis for well watered conditions were obtained from unpublished glasshouse experiments by following anther emergence over time. Normally the dryland thermal estimates were c. $20 \%$ less than for well watered conditions.

Possible improvements in the phenology submodel could be made by adding vernalization, water stress

Table 7. Final thermal estimates for various growth stages for well watered and dryland conditions

\begin{tabular}{lcc} 
Growth stage & $\begin{array}{c}\text { Well watered } \\
\text { conditions }\end{array}$ & $\begin{array}{c}\text { Dryland } \\
\text { conditions }\end{array}$ \\
1 January to single ridge & \multicolumn{2}{c}{ Phyllochrons } \\
Single ridge to double ridge & $1 \cdot 7$ & $1 \cdot 4$ \\
Double ridge to jointing & $1 \cdot 2$ & $1 \cdot 0$ \\
Jointing to booting & $2 \cdot 4$ & $2 \cdot 0$ \\
Booting to heading & $3 \cdot 3$ & $3 \cdot 0$ \\
Heading to anthesis & $1 \cdot 3$ & $1 \cdot 1$ \\
& $0 \cdot 7$ & $0 \cdot 5$ \\
Anthesis duration & \multicolumn{2}{c}{ GDD } \\
Anthesis to maturity & 145 & 120 \\
\hline
\end{tabular}

Growing degree-days (GDD) are measured above a $0^{\circ} \mathrm{C}$ base temperature. For this table, the phyllochron is assumed to be 108.2 GDD in converting from GDD to number of phyllochrons in an interval. 
and cultivar effects on phenology. Differences among cultivars in thermal time between various growth stages seem to exist (Table 5). However, no apparent relationship exists in the rank of cultivars for the amount of thermal time between intervals. For example, Centurk had the least GDD for the two intervals 1 January to jointing and jointing to heading, but had the most GDD from heading to anthesis of all four cultivars. A caveat on the observed data (Table 5) is that the experiment was not designed to test for differences among cultivars, and that these results may erroneously assume that differences between sites, years, and other factors are negligible. Yet the data imply that some simple maturity class factor for shifting the thermal estimates may not improve the model, or the relationship needs to be well quantified for a specific cultivar before application. Haley (1989) places TAM 101, Larned and Scout 66 in the earliest maturity groups and Centurk 78 in one of the latest maturity groups, yet when looking at the interval from 1 January to maturity (Table 5), there is very little difference in GDD between the four cultivars. Also, no relationship was found between maturity groups and the phyllochron (Table 1).

Special thanks goes to D. E. Smika for use of the validation data sets, B. Klepper and R. W. Rickman for many valuable discussions on wheat development and phenology and A. B. Frank, C. M. Grieve, E. V. Maas, R. W. Rickman and J. R. Welsh for reviewing the manuscript.

\section{REFERENCES}

Baker, C. K., Gallagher, J. N. \& Monteith, J. L. (1980). Daylength change and leaf appearance in winter wheat. Plant, Cell and Environment 3, 285-287.

Batten, G. D. \& KHAN, M. A. (1987). Effect of time of sowing on grain yield, and nutrient uptake of wheats with contrasting phenology. Australian Journal of Experimental Agriculture 27, 881-887.

Bauer, A., Frank, A. B. \& Black, A. L. (1983). Correlation of five wheat growth stage scales used in the Great Plains. USDA AAT-NC-7.

BeLford, R. K., KLePPER, B. \& RickMAN, R. W. (1987). Studies of intact shoot-root systems of field-grown winter wheat. II. Root and shoot developmental patterns as related to nitrogen fertilizer. Agronomy Journal 79, 310-319.

Bhullar, S. S. \& JENNER, C. F. (1983). Responses to brief periods of elevated temperature in ears and grains of wheat. Australian Journal of Plant Physiology 10, $549-560$.

BonnetT, O. T. (1966). Inflorescences of maize, wheat, rye, barley, and oats: Their initiation and development. Bulletin of the University of Illinois Agricultural Experiment Station 721.

BoONe, M. Y. L., Rickman, R. W. \& WhisLeR, F. D. (1990). Leaf appearance rates of two winter wheat cultivars under high carbon dioxide conditions. Agronomy Journal 82, $718-724$.

Crofts, H. J., Gardner, W. K. \& Velthuis, R. G. (1984). A phenological evaluation of wheat for South-western Victoria. Australian Journal of Agricultural Research 35 , 521-528.

Delecolle, R., Couvreur, F., Pluchard, F. P. \& VarletGRANCHER, C. (1985). About the leaf-daylength model under French conditions. In Wheat Growth and Modelling (Eds W. Day \& R. K. Atkin), pp. 25-32. New York: Plenum Press.

Delecolle, R., Hay, R. K. M., Guerif, M., Pluchard, P. \& VARLET-Grancher, C. (1989). A method of describing the progress of apical development in wheat, based on the time-course of organogenesis. Field Crops Research 21, $147-160$.

French, V. \& Hodges, T. (1985). Comparison of crop phenology models. Agronomy Journal 77, 170-171.
FRIEND, D. J. C. (1965). Tillering and leaf production in wheat as affected by temperature and light intensity. Canadian Journal of Botany 43, 1063-1076.

Gallagher, J. N. (1979). Field studies of cereal leaf growth. I. Initiation and expansion in relation to temperature and ontogeny. Journal of Experimental Botany $\mathbf{3 0}$. 625-636.

Gallagher, J. N., Biscoe, B. V. \& Wallace, J. S. (1979). Field studies of cereal leaf growth. IV. Winter wheat leaf extension in relation to temperature and leaf water status. Journal of Experimental Botany 30, 657-668.

HALEY, S. (1989). Variation among winter wheats for traits associated with drought resistance. MS thesis, Colorado State University.

HaUn, J. R. (1973). Visual quantification of wheat development. Agronomy Journal 65, 116-119.

HaY, R. K. M. \& Delecolle, R. (1989). The setting of rates of development of wheat plants at crop emergence: influence of the environment on rates of leaf appearance. Annals of Applied Biology 115, 333-341.

HAY, R. K. M. \& WILSON, G. T. (1982). Leaf appearance and extension in field-grown winter wheat plants: the importance of soil temperature during vegetative growth. Journal of Agricultural Science, Cambridge 99, 403-410.

HERzOG, H. (1986). Source and Sink During the Reproductive Period of Wheat. Development and its Regulation With Special Reference to Cytokinins. Berlin: Paul Parey Science Publishers.

Kirby, E. J. M. (1985). Significant stages of ear development in winter wheat. In Wheat Growth and Modelling (Eds W. Day \& R. K. Atkin), pp. 7-24. New York: Plenum Press.

Kirby, E. J. M. \& Perry, M. W. (1987). Leaf emergence rates of wheat in a Mediterranean environment. Australian Journal of Agricultural Research 38, 455-464.

Kirby, E. J. M., Appleyard, M. \& Fellowes, G. (1982). Effect of sowing date on the temperature response of leaf emergence and leaf size in barley. Plant, Cell and Environment 5, 477-484.

Kirby, E. J. M., Appleyard, M. \& Fellowes, G. (1985a). Effect of sowing date and variety on main shoot leaf emergence and number of leaves of barley and wheat. Agronomie 5, 117-126. 
Kirby, E. J. M., Appleyard, M. \& Fellowes, G. (1985b). Leaf emergence and tillering in barley and wheat. Agronomie 5, 193-200.

Kirby, E. J. M., Siddique, K. H. M., Perry, M. W., KaeseHAGEN, D. \& STERN, W. R. (1989). Variation in spikelet initiation and ear development of old and modern Australian wheat varieties. Field Crops Research 20, $113-128$

Klepper, B., Rickman, R. W. \& Peterson, C. M. (1982). Quantitative characterization of vegetative development in small cereal grains. Agronomy Journal 74, 789-792.

Klepper, B., Rickman, R. W. \& Belford, R. K. (1983). Leaf and tiller identification on wheat plants. Crop Science 23, 1002-1004.

KLEPPER, B., BelFord, R. K. \& RickMAN, R. W. (1984). Root and shoot development in winter wheat. Agronomy Journal 76, 117-122.

Klepper, B., Frank, A. B., Bauer, A. \& Morgan, J. A. (1985). Physiological and phenological research in support of wheat yield modeling. In ARS Wheat Yield Project (Coordinator W. O. Willis), pp. 134-150. USDA-ARS, ARS-38. Springfield, VA: National Technical Information Service.

Malvoisin, P. (1984). Organogenesis and growth of the main culm of wheat from sowing to flowering. I. Relationships between leaf growth and the differentiation of young leaves of flowers. Agronomie 4, 557-564.

Masle-Meynard, J. \& Sebillotte, M. (1981). Heterogeneity of a winter wheat stand. I. Concept of stand structure. Agronomie 1, 207-216.

Masoni, A., Ercoli, L. \& Massantini, F. (1990). Relationship between number of days, growing degree days and photothermal units and growth in wheat (Triticum aestivum L.) according to seeding time. Agricollura Mediterranea 120, 41-51.

McMaster, G. S. \& Smika, D. E. (1988). Estimation and evaluation of winter wheat phenology in the central Great Plains. Agricultural and Forest Meteorology 43, 1-18.

McMaster, G. S., KlepPer, B., Rickman, R. W., Wilhelm, W. W. \& WILLIS, W. O. (1991). Simulation of aboveground vegetative development and growth of unstressed winter wheat. Ecological Modeling 53, 189-204.

NutTonson, M. Y. (1948). Some preliminary observations of phenological data as a tool in the study of photoperiodic and thermal requirements of various plant material. In Vernalization and Photoperiodism Symposium (Eds A. E. Murneek \& R. O. Whyte), pp. 129-143. Chronica Botanica.

Nuttonson, M. Y. (1955). Wheat-Climate Relationships. Washington, DC: American Institute of Crop Ecology.

OOSTERHUIS, D. M. (1977). Developmental morphology of the spike of a Rhodesian spring wheat recorded with a scanning electron microscope. Rhodesian Journal of Agricultural Research 15, 65-77.
Rawson, H. M. \& Evans, L. T. (1970). The pattern of grain growth within the ear of wheat. Australian Journal of Biological Science 23, 753-764.

Rawson, H. M., Hindmarsh, J. H., Fischer, R. A. \& Stockman, Y. M. (1983). Changes in leaf photosynthesis with plant ontogeny and relationships with yield per ear in wheat cultivars and 120 progeny. Australian Journal of Plant Physiology 10, 503-514.

RickMAN, R. W. \& KLEPPER, E. L. (1991). Tillering in wheat. In Plant Phenology (Ed T. Hodges), pp. 73-84. Boca Raton: CRC Press.

Ritchie, J. T. \& OTtER, S. (1985). Description and performance of CERES-Wheat: a user-oriented wheat yield model. In ARS Wheat Yield Project (Coordinator W. O. Willis), pp. 159-175. USDA Agricultural Research Service, ARS -38. Springfield, VA: National Technical Information Service.

Saini, A. D., Dadhwal, V. K., Phadnawis, B. N. \& Nanda, R. (1986). Influence of sowing dates on pre-anthesis phenology in wheat. Indian Journal of Agricultural Science 56, 503-511.

SAYEd, H. I. \& Ghandorah, M. O. (1984). Association of grain-filling characteristics with grain weight and senescence in wheat under warm dry conditions. Field Crops Research 9, 323-332.

SPIERTZ, J. H. J. \& Vos, J. (1985). Grain growth of wheat and its limitation by carbohydrate and nitrogen supply. In Wheat Growth and Modelling (Eds W. Day \& R. K. Atkin), pp. 129-142. New York: Plenum Press.

Thomson, W. J. (1986). Effect of sowing date on the development of three winter wheat cultivars. Tests of Agrochemicals and Cultivars, No. 7 (Annals of Applied Biology, Supplement), 182-183.

Vos, J. (1985). Aspects of modelling post-floral growth of wheat and calculations of the effects of temperature and radiation. In Wheat Growth and Modelling (Eds W. Day \& R. K. Atkin), pp. 143-148. New York: Plenum Press.

Weir, A. H., Bragg, P. L., Porter, J. R. \& Rayner, J. H. (1984). A winter wheat crop simulation model without water or nutrient limitations. Journal of Agricultural Science, Cambridge 102, 371-382.

Wiegand, C. L. \& Cuellar, J. A. (1981). Duration of grain filling and kernel weight of wheat as affected by temperature. Crop Science 21, 95-101.

Wilhelm, W. W., McMaster, G. S., Klepper, B. \& Rickman, R. W. (1990). Vegetative development and growth model for wheat. In Climatic Risk in Crop Production: Models and Management for the Semi-Arid Tropics and Subtropics, An International Symposium and Workshop (Eds R. C. Muchow \& J. A. Bellamy), pp. 34-35. Brisbane, Australia: Incitec.

Wright, D. \& Hughes, LL.G. (1987). Relationships between time, temperature, daylength and development in spring barley. Journal of Agricultural Science, Cambridge 109, 365-373. 